06;13

\title{
Исследование изменения микротвердости поверхности циркония после лазерной модифицирующей обработки
}

\author{
() В.И. Проскуряков, И.В. Родионов, В.А. Кошуро \\ Саратовский государственный технический университет им. Гагарина Ю.А., Саратов, Россия \\ E-mail: prosku.94@mail.ru
}

Поступило в Редакцию 16 ноября 2018 г.

В окончательной редакции 16 ноября 2018 г.

Принято к публикации 24 декабря 2018 г.

\begin{abstract}
Приведены результаты исследования процесса лазерного упрочнения циркония марки Е110. Установлено, что при модификации на воздухе происходит формирование равномерно распределенного микрорельефа, характеризуемого наличием микрочастиц различной конфигурации. За счет перекрытия траекторий обработки происходит формирование слоистой структуры. Состав модифицированной поверхности зависит от режимов обработки и в основном включает смесь оксидов и нитридов циркония. Также установлено формирование диффузионных переходных зон между металлом основы и измененным поверхностным слоем. Определена зависимость толщины слоя закалки от режимов импульсного лазерного воздействия.
\end{abstract}

DOI: 10.21883/PJTF.2019.06.47493.17598

Цирконий является химически активным металлом и имеет ряд преимуществ: высокие температура плавления $\left(T=1852^{\circ} \mathrm{C}\right)$ и стойкость к воздействию различных агрессивных сред, повышенные прочностные параметры, малое сечение захватов тепловых нейтронов. Это дает возможность использовать цирконий во многих сферах промышленности: приборостроении, литейном деле, машиностроении и медицинской технике. Циркониевые сплавы являются основой конструкционных материалов активной зоны ядерных реакторов. К сплавам на основе циркония, как и к другим конструкционным материалам, предъявляются высокие требования по механическим характеристикам. В связи с этим большое внимание уделяется повышению механических характеристик циркония, в частности исследованию процессов упрочнения его поверхности [1-3].

В настоящее время известен широкий спектр технологий формирования защитных покрытий, способных обеспечить повышение долговечности циркониевых изделий за счет изменения физико-механических параметров поверхностного слоя. Покрытия на цирконии формируют электрохимическими, газотермическими и электрофизическими методами. Так, методом ионнолучевого осаждения (IBAD) можно осаждать тонкие пленки на обычной подложке при комнатной температуре. Известно, что таким методом на цирконии могут быть получены пленочные покрытия толщиной до $800 \mu \mathrm{m}$ с твердостью 27.45-30.89 GPa [4]. Облучение импульсным электронным пучком (ИЭП) существенным образом влияет на твердость образцов и зависит от параметров пучка. Установлено, что при облучении ИЭП в зависимости от величины плотности энергии в импульсе происходит сглаживание рельефа и структурирование поверхности. После воздействия ИЭП при плотности энергии $20 \mathrm{~J} / \mathrm{cm}^{2}$ твердость поверхностного слоя толщиной 8-10 $\mu \mathrm{m}$ возрастает до $1.96 \mathrm{GPa}$ [5]. Микродуговое оксидирование циркония позволяет получить керамикоподобные оксидные покрытия толщиной от 60 до $300 \mu \mathrm{m}$ с широким комплексом свойств, включающим повышенную износостойкость, коррозионную стойкость, теплостойкость [6]. Газотермическое оксидирование на воздухе в электропечи сопротивления позволяет формировать оксидные покрытия на цирконии, предварительно прошедшем абразивно-струйную обработку, с твердостью до $19.5-0.5 \mathrm{GPa}$, состоящие преимущественно из моноклинной фазы диоксида циркония [7]. Азотирование циркония при парциальном давлении кислорода $(1.5-4) \cdot 10^{-5}$ Torr и температурах подложки $300-600^{\circ} \mathrm{C}$ приводит к образованию на поверхности основы нитридооксидного покрытия повышенной прочности и стойкости к коррозии [8]. Скоростной высокочастотный нагрев циркониевых изделий до температуры $\beta$-фазы с последующей закалкой и отжигом значительно повышает их трещиностойкость (в 2-3 раза), увеличивает сопротивление ползучести, формирует достаточно высокую пластичность до уровня $\sim 650 \pm 20 \mathrm{MPa}[9]$.

Покрытия на поверхности циркония можно получить электрофизическими методами, например лазерной модификацией $[10,11]$. Поверхностное упрочнение происходит за счет фазовых превращений в твердом состоянии в поверхностных слоях при быстром нагреве и последующем охлаждении. Однако изучение особенностей химико-термических механизмов упрочнения циркония в процессе лазерной обработки является актуальным при разработке современных технологий модифицирования.

Поэтому цель настоящей работы заключалась в исследовании изменений характеристик поверхности циркония в результате лазерной модификации и их влияния на микротвердость модифицируемого слоя.

Эксперименты проводились на цирконии марки Е110. Использовались образцы, представляющие собой пластины размером $10 \times 10 \times 3 \mathrm{~mm}$. Исследуемая поверхность подвергалась предварительной шлифовке влагостойкой наждачной бумагой зернистостью $\mathrm{P} 600$ 
(ISO-6344). Затем образцы очищались от технологических загрязнений методом ультразвуковой (УЗ) обработки с использованием УЗ-ванны „Кристалл-2.5“ последовательно в водных растворах поверхностно-активных веществ и этилового спирта в течение $20 \mathrm{~min}$.

В качестве источника лазерного излучения использовалась автоматизированная установка для термофизической когерентной модификации поверхности LRS-50A. Лазерная обработка проводилась при напряжениях $U=350,375,400,425,450$ и $475 \mathrm{~V}$. Длительность $\tau$ импульсного воздействия составляла $0.7,0.85$ и $1 \mathrm{~ms}$. Луч фокусировался в пятно диаметром $1 \mathrm{~mm}$. Сканирование поверхности осуществлялось при частоте следования импульсов излучения $15 \mathrm{~Hz}$ и коэффициенте перекрытия 0.1 .

Структура поверхности покрытия исследовалась методом оптической микроскопии с использованием компьютерной программы графической обработки микроизображений „Metallograph“. При этом анализировались участки поверхности площадью $5 \mathrm{~mm}^{2}$. Микротвердость измерялась с помощью твердомера ПМТ-3М с индентором Виккерса при нагрузке на индентор $1.961 \mathrm{~N}$ (ISO 6507-1:2005). Статистическая обработка результатов исследования проводилась с использованием программы DataFit 9.

Элементный состав и микроморфология модифицируемого слоя исследовались методами энергодисперсионного рентгенофлуоресцентного анализа (ЭДРФА) (погрешность измерения концентраций \pm 0.5 at.\%) и растровой электронной микроскопии (РЭМ) на электронном микроскопе „MIRA II LMU“ с детектором „INCA PentaFETx3“.

Металлографические исследования структуры с помощью РЭМ показали, что помимо формирования высокотвердого поверхностного слоя образуется так называемый слой закалки, твердость которого значительно выше твердости основного металла. На рис. 1 указаны

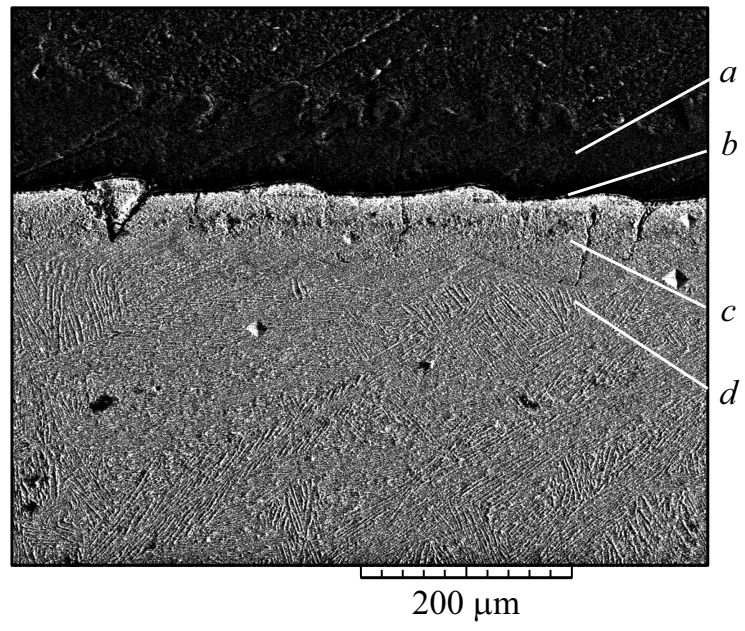

Рис. 1. Микрошлиф образца циркония после лазерной обработки. $a-$ эпоксидная смола, $b-$ полученный модифицируемый слой, $c-$ зона упрочнения (слой закалки), $d-$ основа металла (поле зрения $661.3 \mu \mathrm{m}$ ).

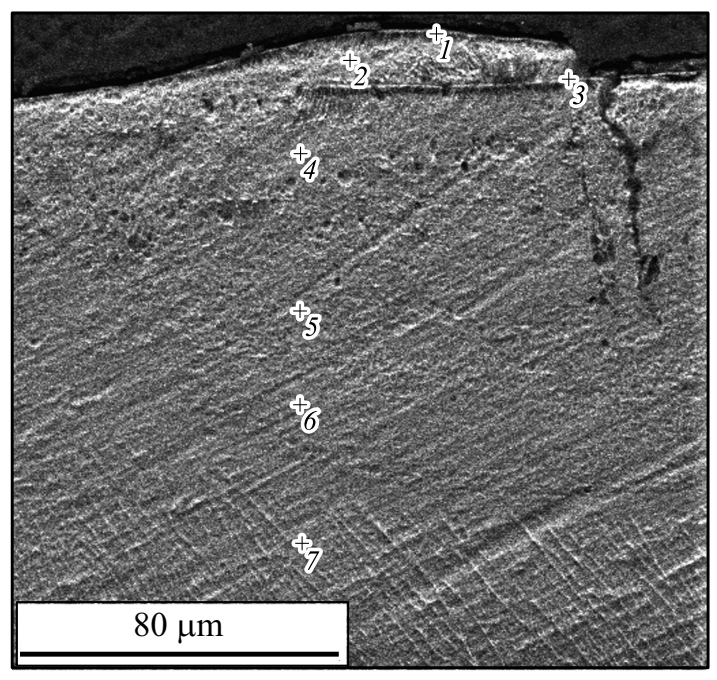

Рис. 2. Микроструктура шлифа поверхностного слоя циркония после лазерной обработки. 1-7 - обозначения спектров (областей), по которым проводился ЭДРФА.

Таблица 1. Элементный состав зоны лазерного упрочнения циркония после лазерной обработки (at.\%)

\begin{tabular}{c|c|c|c|c}
\hline Спектр & $\mathrm{N}$ & $\mathrm{O}$ & $\mathrm{Zr}$ & $\mathrm{W}$ \\
\hline 1 & 14.13 & 45.18 & 40.31 & 0.38 \\
2 & 24.04 & 27.69 & 48.27 & - \\
3 & 7.22 & 51.19 & 41.27 & 0.32 \\
4 & - & 35.31 & 64.69 & - \\
5 & - & 18.71 & 81.29 & - \\
6 & - & 21.91 & 78.09 & - \\
7 & - & 19.10 & 80.90 & -
\end{tabular}

границы слоев, образовавшихся в результате лазерного упрочнения.

Выявлены изменения в составе материала после лазерной обработки. Согласно проведенным спектральным исследованиям шлифа образца из циркония, основными элементами сформированного слоя являются азот (7.22-24.04 at.\%), кислород (27.69-51.19 at.\%), цирконий (40.31-48.27 at.\%) (рис. 2, табл. 1). Кроме того, обнаружено присутствие следового количества вольфрама в диапазоне $(0.32-0.38$ at.\%). Наличие высокого содержания кислорода и азота в зоне лазерной закалки показывает, что формируемый слой упрочненной поверхности является преимущественно нитридооксидным по своему составу после импульсного воздействия.

По результатам измерения микротвердости поперечных микрошлифов циркония установлено, что при заданных режимах работы лазера твердость зоны упрочнения составляет от 6 до $8 \mathrm{GPa}$ при твердости циркониевого образца до лазерного упрочнения $2.6 \pm 0.1 \mathrm{GPa}$. Среднее значение твердости на границе зоны закалки и основного металла равно $3 \mathrm{GPa}$. Вероятно, данная разница в показателях твердости отражает явление наклепа после лазерной обработки и процессы перекристаллизации. 
Таблица 2. Результаты среднестатистических значений микротвердости поверхности образцов циркония, полученных в результате лазерного упрочнения при различных режимах

\begin{tabular}{c|c|c}
\hline$\tau, \mathrm{ms}$ & $U, \mathrm{~V}$ & $H, \mathrm{GPa}$ \\
\hline 0.70 & 350 & $24.49 \pm 0.1$ \\
& 375 & $19.90 \pm 0.1$ \\
& 400 & $27.03 \pm 0.1$ \\
& 425 & $26.85 \pm 0.1$ \\
& 450 & $22.73 \pm 0.1$ \\
& 475 & $21.77 \pm 0.1$ \\
& 350 & $13.67 \pm 0.1$ \\
& 375 & $17.65 \pm 0.1$ \\
& 400 & $16.90 \pm 0.1$ \\
& 425 & $18.60 \pm 0.1$ \\
& 450 & $26.53 \pm 0.1$ \\
& 475 & $26.16 \pm 0.1$ \\
& 350 & $17.62 \pm 0.1$ \\
& 375 & $18.41 \pm 0.1$ \\
& 400 & $19.70 \pm 0.1$ \\
& 425 & $25.50 \pm 0.1$ \\
& 450 & $33.88 \pm 0.1$ \\
& 475 & $23.26 \pm 0.1$
\end{tabular}

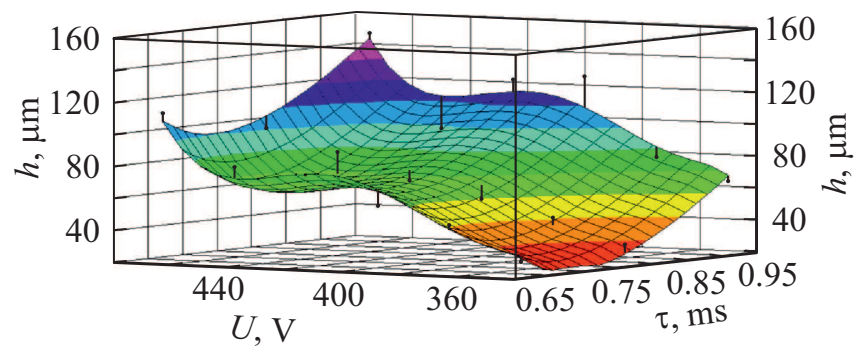

Рис. 3. Зависимость толщины зоны упрочнения (слоя закалки) от режимов лазерной обработки.

Кроме того, были проведены измерения микротвердости самой обработанной поверхности при различных режимах, результаты которых представлены в табл. 2.

Здесь максимальное значение микротвердости составляло $H=33.88 \pm 0.1 \mathrm{GPa}$ и было получено при напряжении $450 \mathrm{~V}$ и длительности импульсного воздействия $1 \mathrm{~ms}$.

В ходе экспериментов было выявлено влияние режимов лазерной обработки на толщину слоя закалки. Установлено, что толщина зоны упрочнения в большей степени зависит от напряжения, а с увеличением длительности импульсного воздействия изменение толщины является незначительным.

С использованием компьютерной программы графической обработки микроизображений „Metallograph“ была определена толщина слоя закалки каждого образца. Затем по полученным результатам построена эмпирическая модель зависимости толщины зоны упрочнения от режимов лазерной обработки (рис. 3).
Построенная эмпирическая модель описывается регрессионным уравнением:

$$
\begin{aligned}
h= & 918937.6+(-1516.8) / x_{1}+588.9 / x_{1}^{2} \\
& +(-1826492612.7) / x_{2}+1449313643120.9 / x_{2}^{2} \\
& +(-573253765977397) / x_{2}^{3}+1.1 / x_{2}^{4}+(-8.8) / x_{2}^{5},
\end{aligned}
$$

где $x_{1}$ - напряжение $(U, \mathrm{~V}) ; x_{2}$ - длительность импульсного воздействия $(\tau, \mathrm{ms})$.

Из данной модели следует, что максимального значения толщина достигает при напряжении от 440 до $460 \mathrm{~V}$ и длительности импульсов $0.85-1 \mathrm{~ms}$, а минимальное значение она принимает при напряжении $340 \mathrm{~V}$ и длительности $0.65-0.7 \mathrm{~ms}$.

Таким образом, лазерная модификация позволила получить на поверхности циркония тонкий высокотвердый слой толщиной $2-5 \mu \mathrm{m}$. По данным РЭМ и результатам измерения микротвердости было установлено образование слоя закалки с измененной структурой толщиной $30-100 \mu \mathrm{m}$, зависящей в большей степени от напряжения импульсов и в меньшей степени от длительности импульсного воздействия.

Исследования выполнены при финансовой поддержке Министерства образования и науки РФ в рамках государственного задания образовательным организациям высшего образования, подведомственным Минобрнауки РФ (проект 11.1943.2017/4.6).

\section{Список литературы}

[1] Пилипенко Н.Н. // Вісник Харків. ун-ту. 2009. Т. 2. № 42. C. $44-50$.

[2] Селезнева Л.В., Бушмин Б.В., Дубровский Ю.В., Хазов И.А., Денисов Е.А., Курдюмов А.А. // Вопр. атомной науки и техники. 2008. № 2. С. 108-111.

[3] Тихов С.В., Горшков О.Н., Павлов Д.А., Антонов И.Н., Бобров А.И., Касаткин А.П., Шенина М.Е. // Письма в ЖТФ. 2014. Т. 40. № 9. С. 9-16.

[4] He X.M., Shu L., Li H.B., Li H.D., Lee S.T. // J. Vacuum Sci. Technol. 1998. V. 16. N 4. P. 2337-2344.

[5] Чернов И.П., Иванова С.В., Кренинг М.Х., Коваль Н.Н., Ларионов В.В., Лидер А.М., Черданщев Ю.П. // ЖТФ. 2012. T. 82. B. 3. C. $81-89$.

[6] Борисов А.М., Востриков В.Г., Романовский Е.А., Ткаченко Н.В., Виноградов А.В., Крит Б.Л., Савушкина С.В., Полянский М.Н. // Поверхность. Рентгеновские, синхротронные и нейтронные исследования. 2013. № 4. С. 76-80.

[7] Проскуряков В.И., Родионов И.В., Кошуро В.А., Егоров И.С. // News of Science and Education. 2017. V. 7. N 3. P. 67-74.

[8] Han J.G., Lee J.S., Kim W., Sun D.S., Chung K.H. // Surface Coat. Technol. 1997. V. 97. N 1-3. P. 492-498.

[9] Стукалов А.И. // Вопр. атомной науки и техники. 2000. № 4. С. $118-129$.

[10] Федоров В.А., Шликова А.А., Яковлев А.В. // Вестн. Тамбов. ун-та. 2017. Т. 22. № 5-2. С. 1100-1108.

[11] Zhu Y., Fu J., Zheng C., Ji Z. // Opt. Laser Technol. 2016. V. 83. P. 21-27. 